\title{
A non-Archie water saturation method for conventional reservoirs based on generalization of Passey TOC model for unconventional reservoirs
}

\author{
Moustafa Oraby ${ }^{1}$
}

Received: 4 March 2020 / Accepted: 24 June 2020 / Published online: 6 July 2020

(c) The Author(s) 2020

\begin{abstract}
The determination of the formation water saturation, $S_{\mathrm{w}}$, is a continuous process throughout the life of the fields. Multiple water saturation models are developed to increase the accuracy of calculating this critical parameter for both open-hole and cased-hole wells. All current open-hole water saturation models require prior knowledge of some field parameters namely; formation water resistivity, $R_{\mathrm{w}}$, clay volume, $V_{\mathrm{c}}$ and rock electrical properties $(m, n)$. It is normally assumed that those reservoir parameters as either constant for the entire reservoir section or change by zones. This is obviously an impractical assumption especially for the $(m)$ and $(n)$ parameters. Also, when a reservoir is under water injection for enhanced oil recovery, the water salinity may change throughout the reservoir, based on the distribution of the reservoir permeability and the salinity of the injected water, resulting in a variable $R_{\mathrm{w}}$. This case represents a real challenge to the existing water saturation models. In this paper, a methodology to determine water saturation without the need for prior knowledge of the formation water resistivity or the rock electrical properties is developed. This approach is a generalization of the Passey total organic carbon, TOC, model which is developed to determine the organic richness of the unconventional reservoirs. The scientific basis of the method, the modification required to be applied in conventional reservoirs, the proof of concept using forward modeled cases and actual field applications in sandstone and carbonate reservoirs are performed to examine the theoretical and the practical applications of the methodology. Excellent results are obtained and discussed.
\end{abstract}

Keywords Water saturation $\cdot$ Non-archie water saturation $\cdot$ Unconventional reservoirs $\cdot$ Passey model

\section{Introduction}

The determination of water saturation is an essential and continuous process for every well, new or old, throughout the lifetime of a reservoir. Incorrect calculations of this critical parameter result in inaccurate field development decisions that will lead to producing high volume of reservoir water or missing potential hydrocarbon zones.

There are multiple water saturation models developed for field applications. All these models are developed to improve the accuracy of determining this critical parameter, $S_{\mathrm{w}}$.

Archie (1942) developed the first water saturation model which took the form

Moustafa Oraby

moustafa.oraby@aucegypt.edu

1 American University in Cairo, Cairo, Egypt

$$
S_{\mathrm{w}}^{n}=\frac{a R_{\mathrm{w}}}{\emptyset^{m} R_{\mathrm{t}}}
$$

where $(m)$ and $(n)$ are defined as cementation and saturation exponents, respectively. The $R_{\mathrm{t}}$ and $\Phi$ represent the resistivity and the porosity of the reservoir rock at each depth. Archie model does not include corrections for the effect of the clay minerals. Clays are conductive minerals that decease the rock resistivity, $R_{\mathrm{t}}$. This reduction in rock resistivity, if not corrected for, will falsely show higher water saturation when Archie model is applied. This was later corrected by multiple researchers using different correction approaches.

Simandoux (1982), Waxman and Smits (1968) and Dual Water model (Clavier et al. 1977) are examples of many methods developed to correct for the clay component effects, volume and types. Simandoux used the clay volume $V_{\mathrm{sh}}$ and the clay resistivity $R_{\mathrm{sh}}$ to correct for the clay conductivity effect. Simandoux model takes the form 
$S_{\mathrm{w}}=\frac{a R_{\mathrm{w}}}{2 \emptyset^{m}}\left[\sqrt{\left(\frac{V_{\mathrm{sh}}}{R_{\mathrm{sh}}}\right)^{2}+\frac{4 \emptyset^{m}}{a R_{\mathrm{w}} R_{\mathrm{t}}}}-\frac{V_{\mathrm{sh}}}{R_{\mathrm{sh}}}\right]$

The Waxman and Smits corrected the clay component effect on Archie model using the cation exchange capacity of clays CEC, and $Q_{\mathrm{v}}$. Their model takes the form

$\frac{1}{R_{\mathrm{t}}}=\emptyset_{\mathrm{t}}^{m} S_{\mathrm{wt}}^{n}\left(\frac{1}{R_{\mathrm{w}}}+\frac{B Q_{\mathrm{v}}}{S_{\mathrm{wt}}}\right)$

The dual water model differentiated between the clay water resistivity $R_{\mathrm{wb}}$ and the formation water resistivity $R_{\mathrm{wf}}$ to perform the correction. The model takes the form

$\frac{1}{R_{\mathrm{t}}}=\emptyset_{\mathrm{t}}^{m} S_{\mathrm{wt}}^{n}\left[\frac{1}{R_{\mathrm{wf}}}+\frac{S_{\mathrm{wb}}}{S_{\mathrm{wt}}}\left(\frac{1}{R_{\mathrm{wb}}}-\frac{1}{R_{\mathrm{wf}}}\right)\right]$

Despite that the above models corrected the effect of the clay conductivity on the Archie model, all still require accurate values for the Archie parameters, $R_{\mathrm{w}}, \mathrm{m}$ and $\mathrm{n}$. In field applications, when Archie and/or the clay corrected models are used, those parameters are kept constants across the entire reservoir section or change them, by zone, based on the measured laboratory values.

In this paper, a method to determine the water saturation without the need of knowing these parameters is discussed. The scientific basis of the approach is derived using forward modeling of multiple cases including

1 Clean formation with variable porosity.

2 Formations with variable clay volumes.

3 Formations with variable pore structure.

The methodology is also tested on field data for both clastics and carbonates reservoirs and compared to the Archiebased water saturation models.

\section{Basis of the methodology}

The methodology is a modification of the Passey (1990, 2010, 2012) Total Organic Carbon model which is widely used to determine the organic richness of the unconventional reservoir.

It is based on characterizing the behavior of two independent measurements that are affected by the existence of hydrocarbon in the rock porosity. These measurements are the rock resistivity and the bulk density or the rock resistivity and the sonic travel time.

The resistivity, bulk density and sonic travel time measurements are affected by the existence of the hydrocarbon in the pore space as follows
1 The resistivity of the formation rock increases with the increase in the hydrocarbon volume in response to the high resistivity of the hydrocarbon compared to that of the salty formation water.

2 The bulk density of the formation rock decreases with the increase in the hydrocarbon volume since the density of the hydrocarbon is less than that of the formation water.

3 The sonic travel time of the formation rock increases with the increase in the hydrocarbon volume since the travel time of hydrocarbon is higher than that of the formation water.

When the resistivity is plotted with either the bulk density or the sonic travel time, in the same plot, a separation is clearly observed and varies with the hydrocarbon saturation. To calibrate this separation, the overlay plot must have a Base Zone with no separation due to the absence of hydrocarbon. This can be achieved using either a clay zone or a water zone where the water saturation in these two zones is a $100 \%$. The overlay technique is investigated using a forward modeling of the resistivity, bulk density and sonic travel time.

The forward modeling of the resistivity, density and sonic travel time for a limestone formation of variable porosity, variable clay volume and variable pore structure are performed. The formation is topped with a Kaolinite clay zone with a resistivity of $3.0 \Omega$, density of $2.5 \mathrm{~g} / \mathrm{cc}$ and sonic travel time of $70 \mathrm{us} / \mathrm{ft}$ as shown in Fig. 1. The clay zone is the base zone for the overlay where its clay parameters are obtained from service companies tools responses handbooks for the Kaolinite clays.

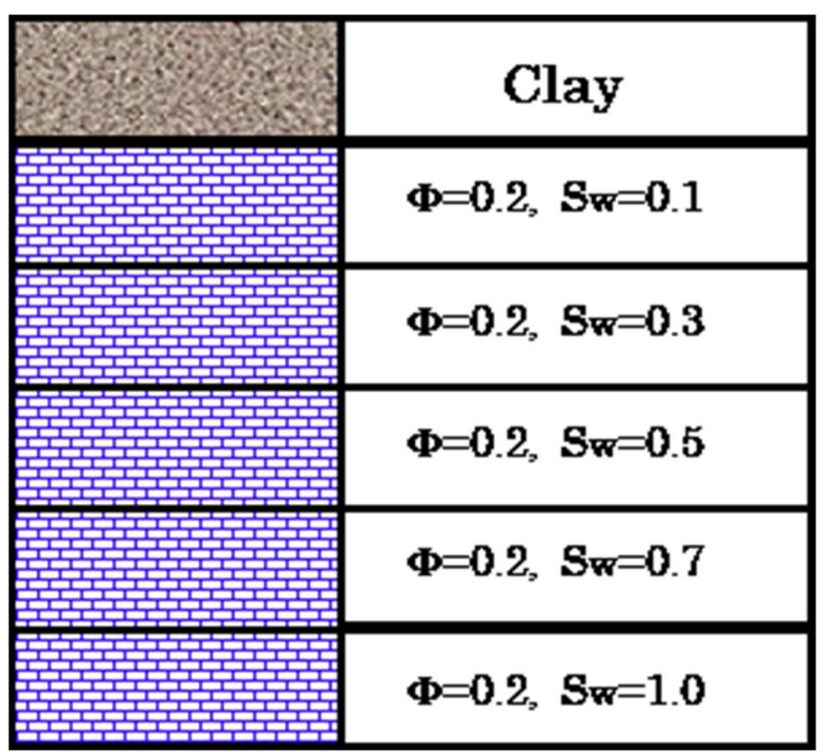

Fig. 1 Illustration model 
The formation resistivity is calculated using the Simandoux equation as

$\frac{1}{R_{\mathrm{t}}}=\frac{a R_{\mathrm{w}}}{4 \emptyset^{m}}\left[\left(\frac{2 \emptyset^{m} S_{\mathrm{w}}}{a R_{\mathrm{w}}}+\frac{V_{\mathrm{sh}}}{R_{\mathrm{sh}}}\right)^{2}-\left(\frac{V_{\mathrm{sh}}}{R_{\mathrm{sh}}}\right)^{2}\right]$

while the sonic travel time and the bulk density are calculated using the Wyllie and the bulk density equations, respectively. The water density and resistivity are $1.035 \mathrm{~g} /$ cc and $0.131 \Omega @ 75$ Fahrenheit for a water salinity of 50 $\mathrm{Kppm}$. The oil density is $0.8 \mathrm{~g} / \mathrm{cc}$, and the limestone formation density is $2.71 \mathrm{~g} / \mathrm{cc}$. The travel time for water and oil is $189 \mathrm{us} / \mathrm{ft}$ and $230 \mathrm{us} / \mathrm{ft}$, while the travel time for limestone is $47 \mathrm{us} / \mathrm{ft}$.

\section{Clean formation case}

Table 1 contains the first modeled case, clean formation $V_{\mathrm{c}}=0 \%, \Phi=30 \%$ for variable hydrocarbon saturations from 10 to $90 \%$ with a $5 \%$ step.

\section{The overlay technique}

Figure 2 shows the resistivity-density overlay where the resistivity is plotted on a logarithmic scale, while the density is plotted linearly. The minimum and the maximum values of the density scale are chosen so that the clay points, resistivity and density overlay. The overlay shows clear separation

Table 1 Rock responses

\begin{tabular}{lrrlr}
\hline & \multicolumn{1}{c}{$S_{\mathrm{w}}$} & \multicolumn{1}{c}{ RT } & Bulk density & Travel time \\
\hline Clay & & 3.0 & 2.500 & 70.0 \\
& 0.10 & 145.6 & 2.144 & 100.7 \\
& 0.15 & 64.7 & 2.148 & 100.1 \\
0.20 & 36.4 & 2.151 & 99.4 \\
0.25 & 23.3 & 2.155 & 98.8 \\
0.30 & 16.2 & 2.158 & 98.2 \\
0.35 & 11.9 & 2.162 & 97.6 \\
0.40 & 9.1 & 2.165 & 97.0 \\
0.45 & 7.2 & 2.169 & 96.4 \\
0.50 & 5.8 & 2.172 & 95.8 \\
0.55 & 4.8 & 2.176 & 95.1 \\
0.60 & 4.0 & 2.179 & 94.5 \\
0.65 & 3.4 & 2.183 & 93.9 \\
0.70 & 3.0 & 2.186 & 93.3 \\
0.75 & 2.6 & 2.190 & 92.7 \\
0.80 & 2.3 & 2.193 & 92.1 \\
0.85 & 2.0 & 2.197 & 91.4 \\
0.90 & 1.8 & 2.200 & 90.8 \\
0.95 & 1.6 & 2.204 & 90.2 \\
1.00 & 1.5 & 2.208 & 89.6 \\
\hline
\end{tabular}

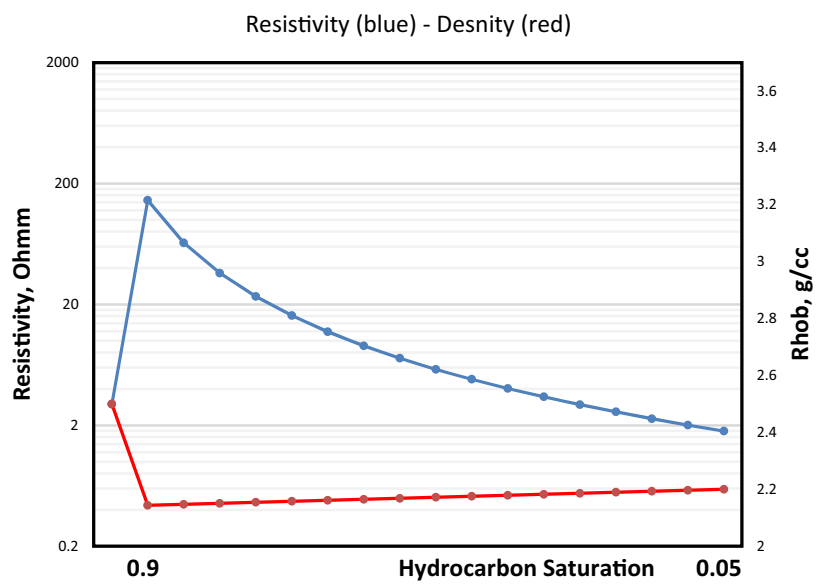

Fig. 2 Density-resistivity overlay, $V_{\mathrm{c}}=0, \Phi=30 \%$

due to the hydrocarbon effect on both measurements. The separation increases with the increase in the hydrocarbon saturation and decreases with the increase in the water saturation.

Similarly, the resistivity and sonic are also overlaid as shown in Fig. 3. The scale of the sonic travel time is reversed since the sonic travel time increases with the increase in the hydrocarbon volume. The scale of the sonic is also chosen to show no separation at the clay zone. The same separation phenomenon is observed where it increases with the increase in the hydrocarbon saturation.

\section{Effect of formation porosity}

To study the effect of formation porosity on the methodology, the forward modeling for the clean formation is repeated but with low porosity, $\Phi=10 \%$.

Table 2 contains the modeled case with variable hydrocarbon saturations from 10 to $90 \%$ with a $5 \%$ step.

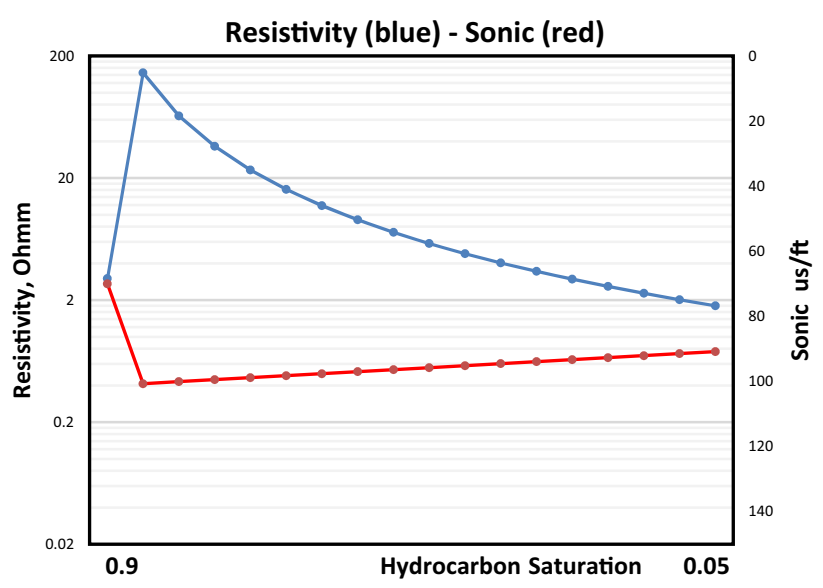

Fig. 3 Sonic-resistivity overlay, $V_{\mathrm{c}}=0, \Phi=30 \%$ 
Table 2 Rock responses

\begin{tabular}{lrrll}
\hline & \multicolumn{1}{l}{$S_{\mathrm{w}}$} & \multicolumn{1}{c}{$\mathrm{RT}$} & Bulk density & Travel time \\
\hline Clay & & 3.0 & 2.500 & 70 \\
& 0.10 & 1310.1 & 2.521 & 64.89 \\
0.15 & 582.3 & 2.523 & 64.685 \\
0.20 & 327.5 & 2.524 & 64.48 \\
0.25 & 209.6 & 2.525 & 64.275 \\
0.30 & 145.6 & 2.526 & 64.07 \\
0.35 & 106.9 & 2.527 & 63.865 \\
0.40 & 81.9 & 2.528 & 63.66 \\
0.45 & 64.7 & 2.530 & 63.455 \\
0.50 & 52.4 & 2.531 & 63.25 \\
0.55 & 43.3 & 2.532 & 63.045 \\
0.60 & 36.4 & 2.533 & 62.84 \\
0.65 & 31.0 & 2.534 & 62.635 \\
0.70 & 26.7 & 2.535 & 62.43 \\
0.75 & 23.3 & 2.537 & 62.225 \\
0.80 & 20.5 & 2.538 & 62.02 \\
0.85 & 18.1 & 2.539 & 61.815 \\
0.90 & 16.2 & 2.540 & 61.61 \\
0.95 & 14.5 & 2.541 & 61.405 \\
1.00 & 13.1 & 2.543 & 61.2 \\
\hline
\end{tabular}

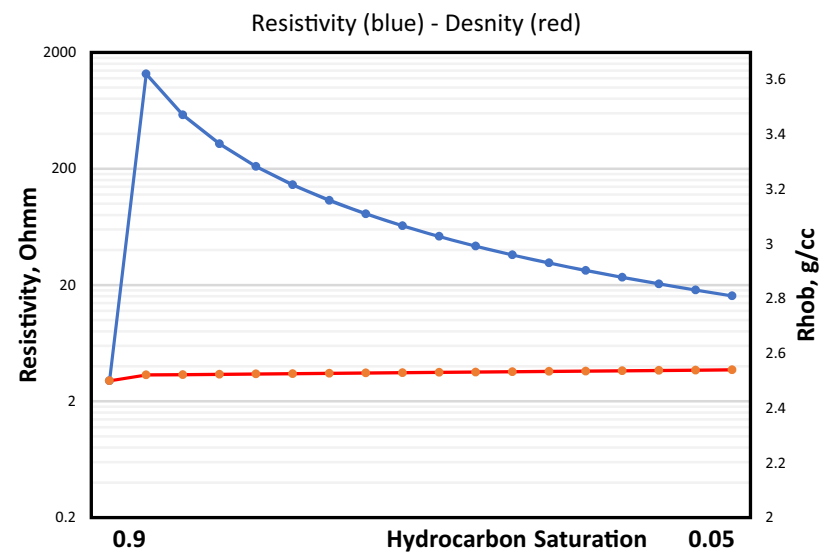

Fig. 4 Density-resistivity overlay, $V_{\mathrm{c}}=0, \Phi=10 \%$

Figures 4 and 5 show the separation between the resistivity and the density, and the separation between the resistivity and the sonic. The overlay shows clear separation due to the hydrocarbon effect on both measurements. The separation increases with the increase in the hydrocarbon saturation and decreases with the increase in the water saturation

This forward modeled case showed that the values of the resistivity, density and sonic changed due to the

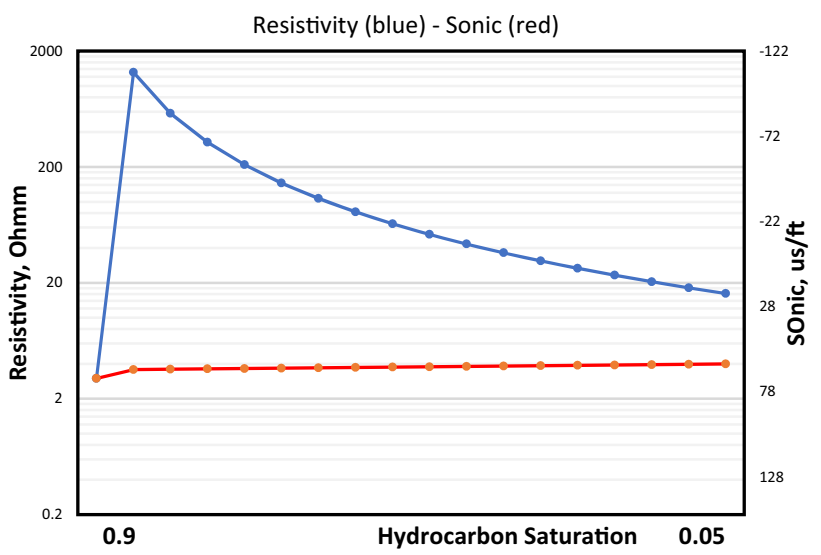

Fig. 5 Sonic-resistivity overlay, $V_{\mathrm{c}}=0, \Phi=10 \%$

Table 3 Rock responses with, $V_{\mathrm{c}}=25 \%, \Phi=30 \%$

\begin{tabular}{lrrrr}
\hline & $S_{\mathrm{w}}$ & $\mathrm{RT}$ & Bulk density & Travel time \\
\hline Clay & & 3.0 & 2.500 & 70.0 \\
& 0.10 & 62.2 & 2.092 & 106.4 \\
0.15 & 33.4 & 2.095 & 105.8 \\
0.20 & 21.0 & 2.099 & 105.2 \\
0.25 & 14.4 & 2.102 & 104.6 \\
0.30 & 10.6 & 2.106 & 104.0 \\
0.35 & 8.1 & 2.109 & 103.3 \\
0.40 & 6.4 & 2.113 & 102.7 \\
0.45 & 5.1 & 2.116 & 102.1 \\
0.50 & 4.2 & 2.120 & 101.5 \\
0.55 & 3.6 & 2.123 & 100.9 \\
0.60 & 3.0 & 2.127 & 100.3 \\
0.65 & 2.6 & 2.130 & 99.7 \\
0.70 & 2.3 & 2.134 & 99.0 \\
0.75 & 2.0 & 2.137 & 98.4 \\
0.80 & 1.8 & 2.141 & 97.8 \\
0.85 & 1.6 & 2.144 & 97.2 \\
0.90 & 1.4 & 2.148 & 96.6 \\
0.95 & 1.3 & 2.151 & 96.0 \\
1.00 & 1.2 & 2.155 & 95.4 \\
\hline & & &
\end{tabular}

change of porosity, but the separation phenomenon is still valid.

\section{Effects of clay minerals}

To study the effect of clay minerals on the methodology and its separation phenomenon, the forward modeling for the first clean formation is repeated but with adding variable clay volumes; $25 \%$ and $50 \%$, respectively. The clay compaction factor, $C_{\mathrm{p}}=\Delta t_{\mathrm{sh}} / 100$, for the Wyllie equation is used to correct for the effect of clays on the modeled sonic travel time. Table 3 contains the modeled case of a 
Resistivity (blue) - Desnity (red)

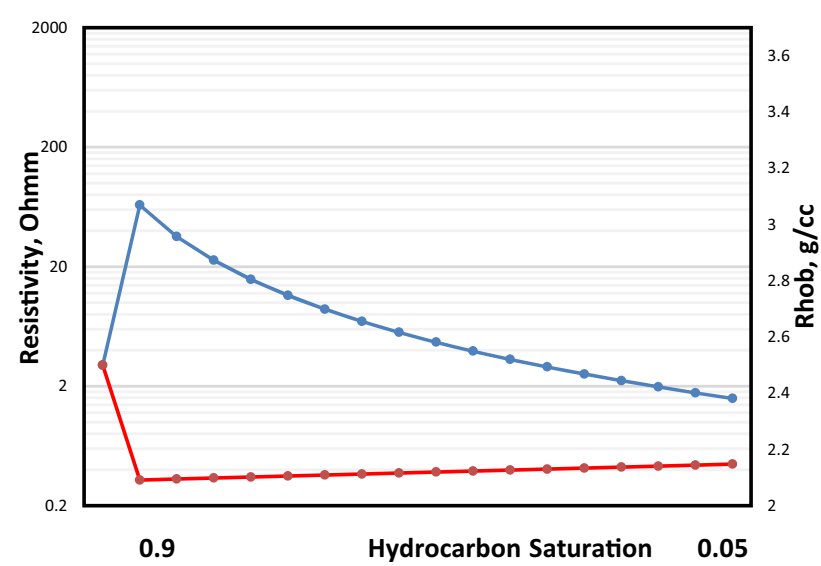

Fig. 6 Density-resistivity overlay, $V_{\mathrm{c}}=25 \%, \Phi=30 \%$

Resistivity (blue) - Sonic (red)

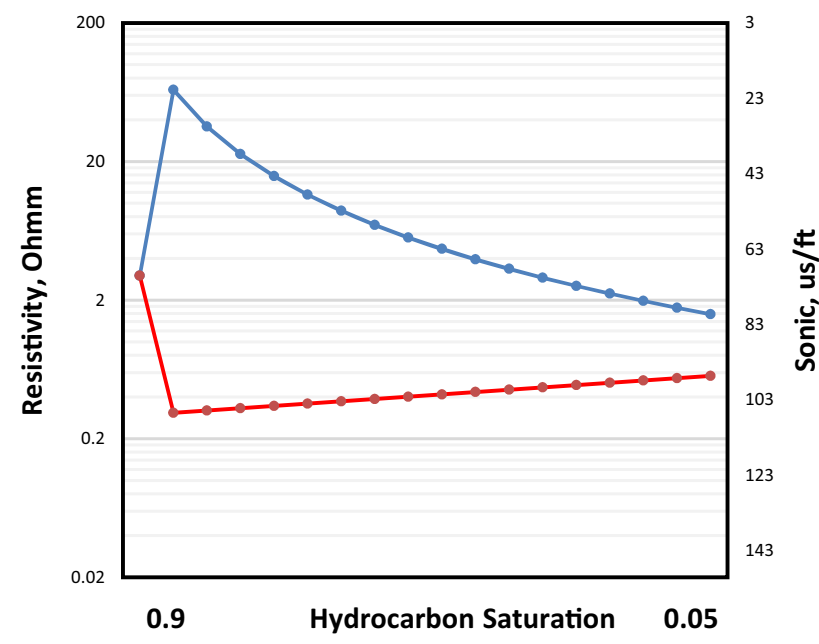

Fig. 7 Sonic-resistivity overlay, clay $=25 \%, \Phi=30 \%$

clay volume, $V_{\mathrm{c}}=25 \%$, and variable hydrocarbon saturations from 10 to $90 \%$ with a $5 \%$ step.

Figures 6 and 7 show the separation between the resistivity and the density, and the separation between the resistivity and the sonic respectively for the $25 \%$ clay volume case.

Table 4 contains the modeled case of a formation with a clay volume, $V_{\mathrm{c}}=50 \%$, and variable hydrocarbon saturations from 10 to $90 \%$ with a $5 \%$ step. Figures 8 and 9 show the separation between the resistivity and the density, and the separation between the resistivity and sonic, respectively.

These two modeled cases of variable clay volumes clearly show that the values of the resistivity, density
Table 4 Rock responses with, $V_{\mathrm{c}}=50 \%, \Phi=30 \%$

\begin{tabular}{llrlc}
\hline & $S_{\mathrm{w}}$ & \multicolumn{1}{c}{ RT } & Bulk density & Travel time \\
\hline Clay & & 3.0 & 2.500 & 70.0 \\
& 0.10 & 41.1 & 2.039 & 112.2 \\
& 0.15 & 23.6 & 2.043 & 111.6 \\
0.20 & 15.5 & 2.046 & 110.9 \\
0.25 & 11.1 & 2.050 & 110.3 \\
0.30 & 8.4 & 2.053 & 109.7 \\
0.35 & 6.5 & 2.057 & 109.1 \\
0.40 & 5.2 & 2.060 & 108.5 \\
0.45 & 4.3 & 2.064 & 107.9 \\
0.50 & 3.6 & 2.067 & 107.3 \\
0.55 & 3.1 & 2.071 & 106.6 \\
0.60 & 2.6 & 2.074 & 106.0 \\
0.65 & 2.3 & 2.078 & 105.4 \\
0.70 & 2.0 & 2.081 & 104.8 \\
0.75 & 1.8 & 2.085 & 104.2 \\
0.80 & 1.6 & 2.088 & 103.6 \\
0.85 & 1.4 & 2.092 & 102.9 \\
0.90 & 1.3 & 2.095 & 102.3 \\
0.95 & 1.2 & 2.099 & 101.7 \\
1.00 & 1.1 & 2.103 & 101.1 \\
\hline
\end{tabular}

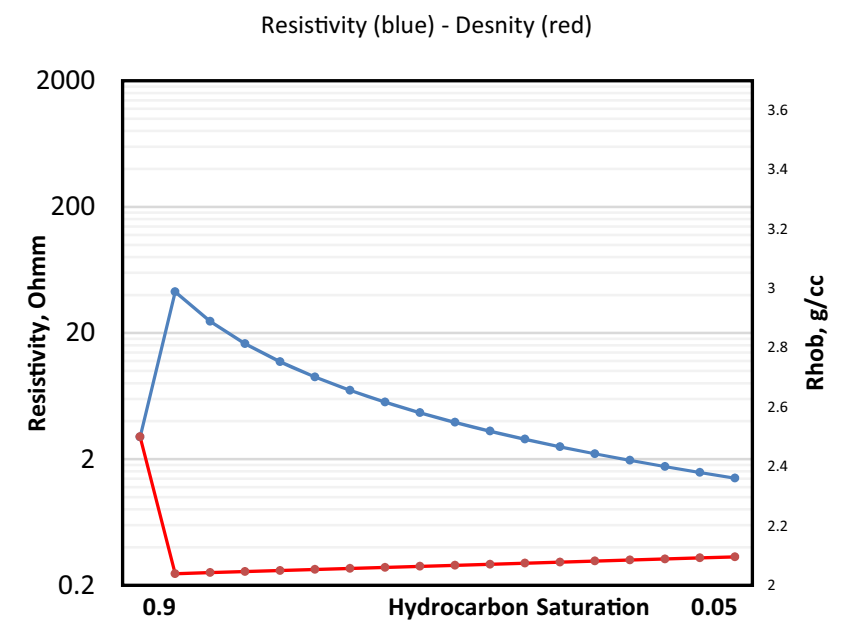

Fig. 8 Density-resistivity overlay, $V_{\mathrm{c}}=50 \%, \Phi=30 \%$

and sonic are changing, but the separation phenomenon still holds.

\section{Effect of pore structure}

Focke and Munn (1987) found that the difference between an inter-particle and vuggy pore system for carbonate reservoirs in the Middle East can be seen in the values of the cementation exponent ' $\mathrm{m}$ '. The ' $\mathrm{m}$ ' value can be as large as $m=4$ for the vuggy pore structure versus $m=2$ for the 
Resistivity (blue) - Sonic (red)

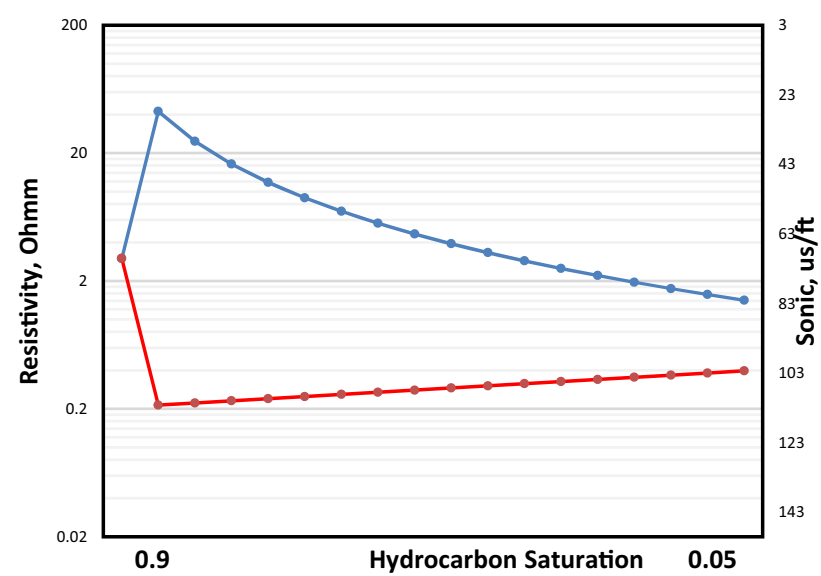

Fig. 9 Sonic-resistivity overlay, clay $=50 \%$

Table 5 Rock responses with clay, $V_{\mathrm{c}}=25 \%$ and $m=2$

\begin{tabular}{lrrlc}
\hline & \multicolumn{1}{c}{$S_{\mathrm{w}}$} & $\mathrm{RT}$ & Bulk density & Travel time \\
\hline Clay & & 3.0 & 2.500 & 70.0 \\
& 0.10 & 62.2 & 2.092 & 106.4 \\
0.15 & 33.4 & 2.095 & 105.8 \\
0.20 & 21.0 & 2.099 & 105.2 \\
0.25 & 14.4 & 2.102 & 104.6 \\
0.30 & 10.6 & 2.106 & 104.0 \\
0.35 & 8.1 & 2.109 & 103.3 \\
0.40 & 6.4 & 2.113 & 102.7 \\
0.45 & 5.1 & 2.116 & 102.1 \\
0.50 & 4.2 & 2.120 & 101.5 \\
0.55 & 3.6 & 2.123 & 100.9 \\
0.60 & 3.0 & 2.127 & 100.3 \\
0.65 & 2.6 & 2.130 & 99.7 \\
0.70 & 2.3 & 2.134 & 99.0 \\
0.75 & 2.0 & 2.137 & 98.4 \\
0.80 & 1.8 & 2.141 & 97.8 \\
0.85 & 1.6 & 2.144 & 97.2 \\
0.90 & 1.4 & 2.148 & 96.6 \\
0.95 & 1.3 & 2.151 & 96.0 \\
1.00 & 1.2 & 2.155 & 95.4 \\
\hline & & &
\end{tabular}

inter-particle pore structure. This finding is used here to study the effect of the change in the pore structure on the separation phenomenon.

Table 5 contains the modeled case of a carbonate formation with clay volume $V_{\mathrm{c}}=25 \%, m=2$ representing interparticle pore structure with variable hydrocarbon saturations from 10 to $90 \%$ with a $5 \%$ step, while Table 6 contains the modeled case of a formation with clay volume of $V_{\mathrm{c}}=25 \%$, $m=4$ representing vuggy pore structure, and variable
Table 6 Rock responses with clay effect, $V_{\mathrm{c}}=25 \%, m=4$

\begin{tabular}{lrrrr}
\hline & $S_{\mathrm{w}}$ & \multicolumn{1}{c}{ RT } & Bulk density & Travel time \\
\hline Clay & & 3.0 & 2.500 & 70.000 \\
& 0.10 & 111.7 & 2.092 & 106.420 \\
0.15 & 72.0 & 2.095 & 105.805 \\
0.20 & 52.2 & 2.099 & 105.190 \\
0.25 & 40.5 & 2.102 & 104.575 \\
0.30 & 32.7 & 2.106 & 103.960 \\
0.35 & 27.2 & 2.109 & 103.345 \\
0.40 & 23.1 & 2.113 & 102.730 \\
0.45 & 20.0 & 2.116 & 102.115 \\
0.50 & 17.5 & 2.120 & 101.500 \\
0.55 & 15.5 & 2.123 & 100.885 \\
0.60 & 13.8 & 2.127 & 100.270 \\
0.65 & 12.5 & 2.130 & 99.655 \\
0.70 & 11.3 & 2.134 & 99.040 \\
0.75 & 10.3 & 2.137 & 98.425 \\
0.80 & 9.4 & 2.141 & 97.810 \\
0.85 & 8.7 & 2.144 & 97.195 \\
0.90 & 8.0 & 2.148 & 96.580 \\
0.95 & 7.4 & 2.151 & 95.965 \\
1.00 & 6.9 & 2.155 & 95.350 \\
\hline
\end{tabular}

Resistivity (blue) - Desnity (red)

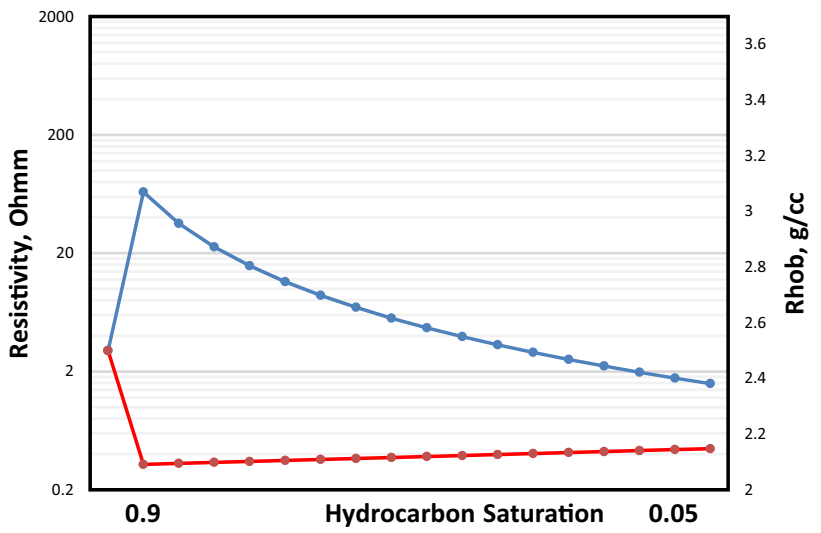

Fig. 10 Density-resistivity overlay, clay $=25 \%, m=2$

hydrocarbon saturations from 10 to $90 \%$ with a $5 \%$ step. Figures 10, 11, 12 and 13 show the separation between the resistivity and the density, and the separation between the resistivity and the sonic respectively for the modeled cases. It is found that the separation phenomenon still holds. 
Resistivity (blue) - Sonic (red)

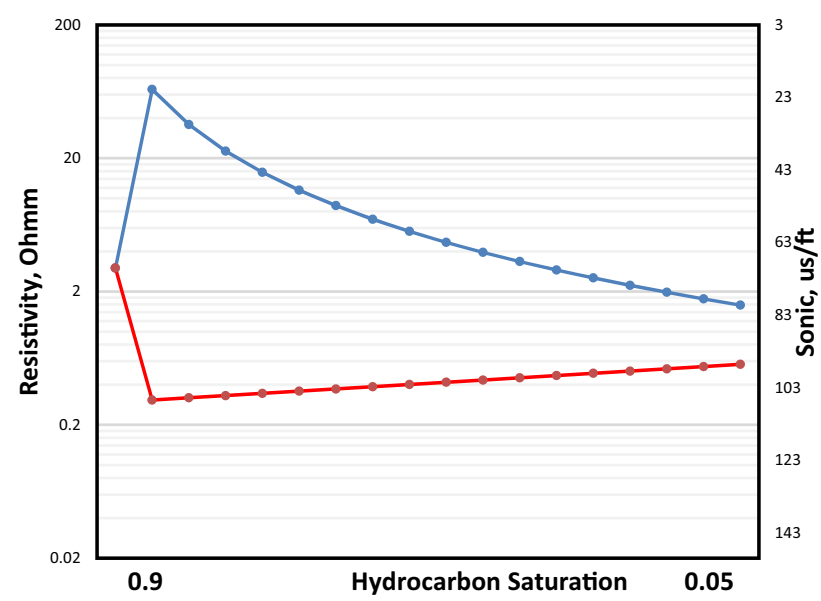

Fig. 11 Sonic-resistivity overlay, clay $=25 \%, m=2$

Resistivity (blue) - Desnity (red)

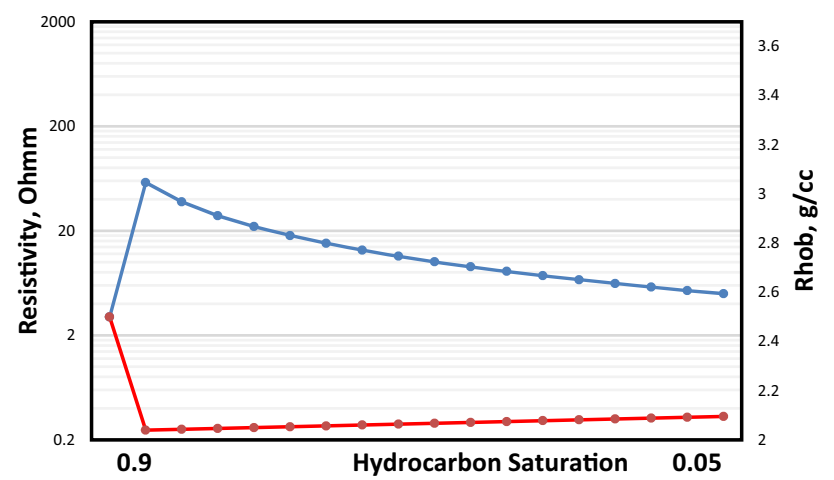

Fig. 12 Density-resistivity overlay, clay $=25 \%, m=4$

Resistivity (blue) - Sonic (red)

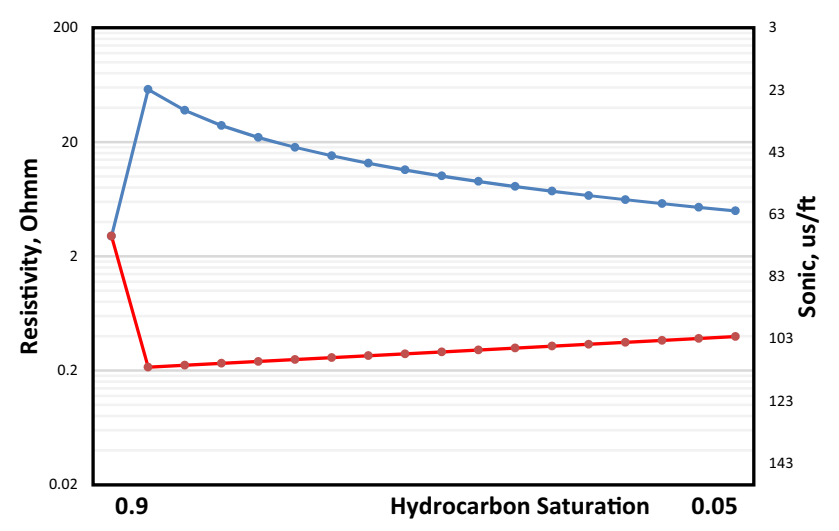

Conclusions of the variable modeling cases

All modeled cases using variable porosity values, clay volumes and pore structure showed that the separation phenomenon holds for all cases.

\section{Water saturation determination}

The separation between the two measurements, resistivity-density and resistivity-sonic, is quantified to determine the hydrocarbon saturation and accordingly the water saturation. The quantification uses the clay point as the reference point where the separation is zero due to zero hydrocarbon in the clay zones. The base zone has a resistivity $R_{b}$, density $\rho_{b}$ in case of the bulk density overlay and $\Delta \mathrm{T}_{\mathrm{b}}$ in case of sonic travel time overlay.

The difference between the resistivity at any point and the base resistivity is defined as $\Delta \mathrm{R}$ and equals

$\Delta R=\log (R)-\log \left(R_{\mathrm{b}}\right)=\log \left(\frac{R}{R_{\mathrm{b}}}\right)$

Similarly, for the density and the sonic the differences $\Delta \rho$ and $\Delta(\Delta T)$ equal

$\Delta \rho=\alpha_{\rho}\left(\rho-\rho_{\mathrm{b}}\right)$

$\Delta(\Delta T)=\alpha_{\Delta T}\left(\Delta T-\Delta T_{\mathrm{b}}\right)$

The factors $\alpha_{\rho}$ and $\alpha_{\Delta T}$ are the transformation factors, for the density and the sonic respectively, from linear to logarithmic scale.

They are calculated as

$\alpha_{\rho}=\frac{n}{\rho_{\max }-\rho_{\min }}$

$\alpha_{\Delta T}=\frac{n}{\Delta T_{\max }-\Delta T_{\min }}$

where $n$ is the number of logarithmic decades. For example, $n=3$ if the resistivity scale is $0.2-200$ and $n=4$ if the resistivity scale is from 0.2 to 2000 .

The hydrocarbon saturation is proportional to the sum of the separations of the two measurements $\Delta R$ and $\Delta \rho$ or $\Delta R$ and $\Delta(\Delta T)$ from the base zone as follows

$S_{\mathrm{hc}} \propto(\Delta R+\Delta \rho)$

$S_{\mathrm{hc}} \propto(\Delta R+\Delta(\Delta T))$

Passey, in his unconventional applications, assumed that the correlation between, $S_{\mathrm{hc}}$, and the separation is linear

Fig. 13 Sonic-resistivity overlay, clay $=25 \%, m=4$ 


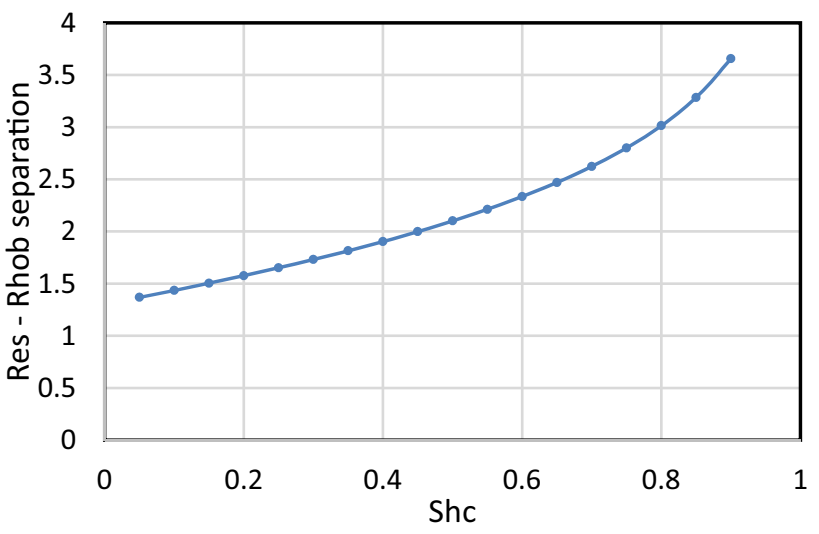

Fig. $14 S_{\mathrm{hc}}$ versus separation for $V_{\mathrm{c}}=0, m=2, \Phi=0.3$

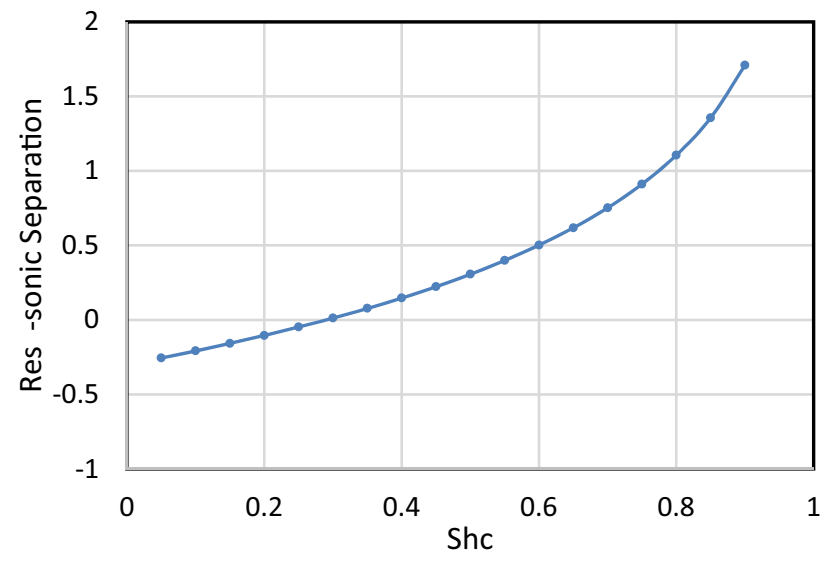

Fig. $15 S_{\mathrm{hc}}$ versus separation for $V_{\mathrm{c}}=0, m=2, \Phi=0.3$

$S_{\mathrm{hc}} \propto(\Delta R+\Delta \rho) \rightarrow S_{\mathrm{hc}}=C_{\rho}(\Delta R+\Delta \rho)$

$S_{\mathrm{hc}} \propto(\Delta R+\Delta(\Delta T)) \rightarrow S_{\mathrm{hc}}=C_{\Delta T}(\Delta R+\Delta(\Delta T))$

The parameter $C$ in Passey model is determined using the level of maturity, LOM, of the organic material. It takes the form

$C=e^{2.297-0.688 * L O M}$

The linear assumption of Passey model showed to be applicable in the unconventional reservoirs but not in conventional reservoirs. To prove this conclusion, the separation values and their corresponding water saturation values are plotted using all the forwarded model examples. Figures 14 and 15 show the nonlinear correlations for the case of no clay, $m=2$ and $\Phi=30 \%$ representing clean formation and inter-particle pore structure. The two figures show that the relationship is nonlinear for both

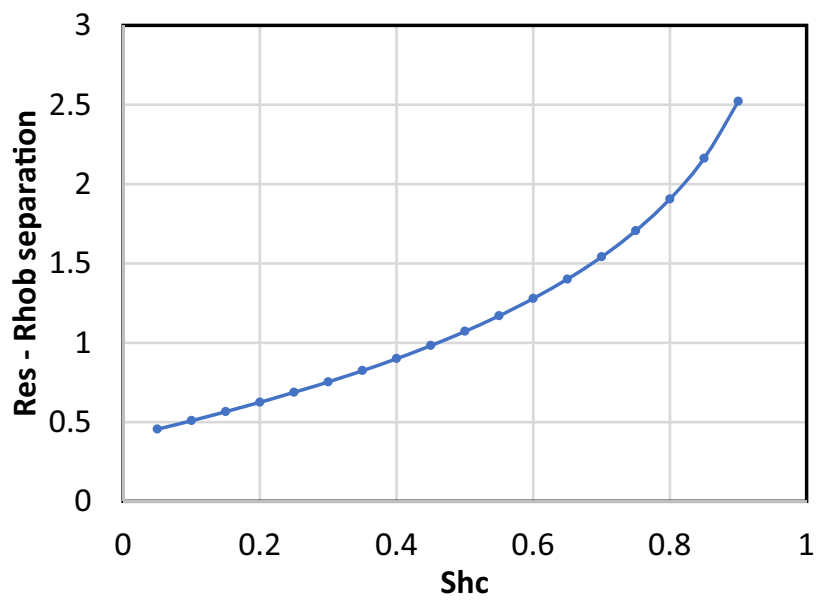

Fig. $16 S_{\mathrm{hc}}$ versus separation for $V_{\mathrm{c}}=0, m=2, \Phi=0.1$

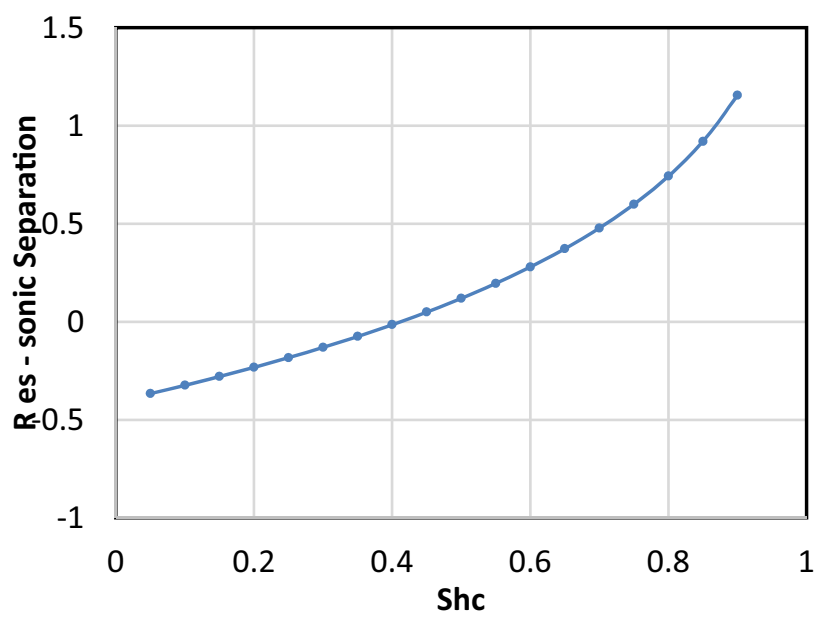

Fig. $17 S_{\mathrm{hc}}$ versus separation for $V_{\mathrm{c}}=0, \boldsymbol{m}=2, \Phi=0.1$

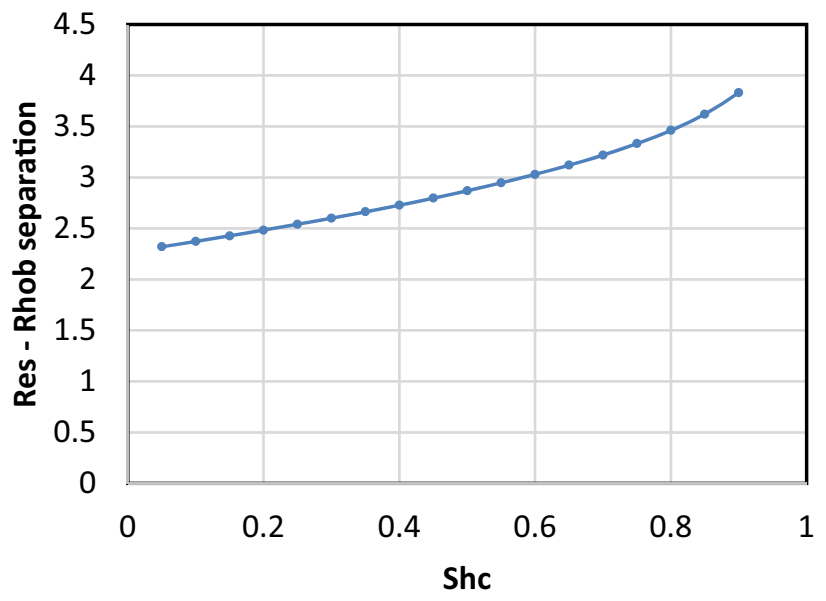

Fig. $18 S_{\mathrm{hc}}$ versus separation for $V_{\mathrm{c}}=025 \%, m=2$ 


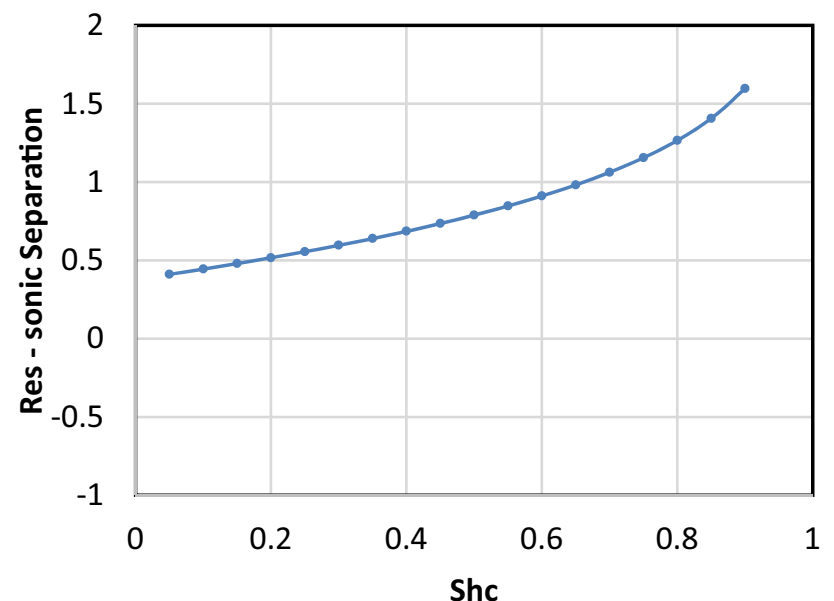

Fig. $19 S_{\mathrm{hc}}$ versus separation for $V_{\mathrm{c}}=25 \%, m=2$

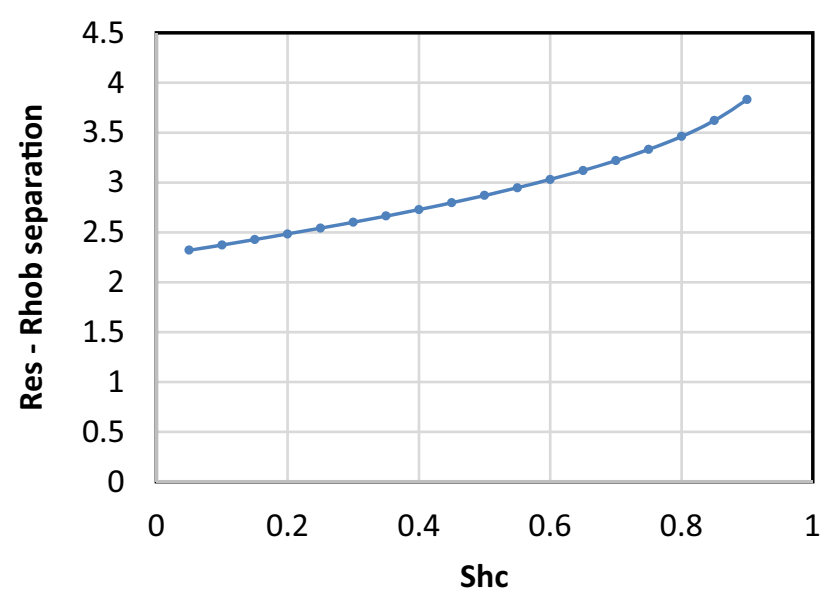

Fig. $20 S_{\mathrm{hc}}$ versus separation for $V_{\mathrm{c}}=50 \%, m=2$

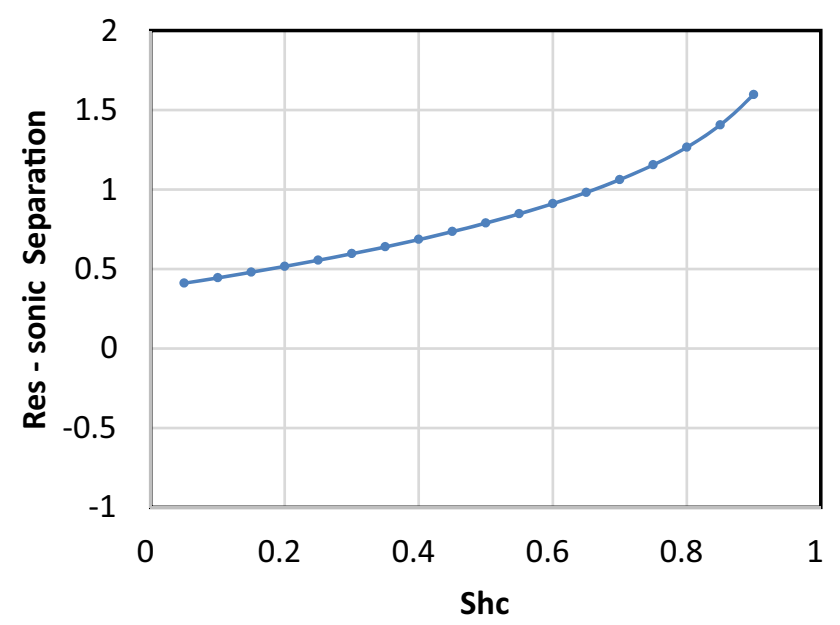

Fig. $21 S_{\mathrm{hc}}$ versus separation for $V_{\mathrm{c}}=0, m=2$

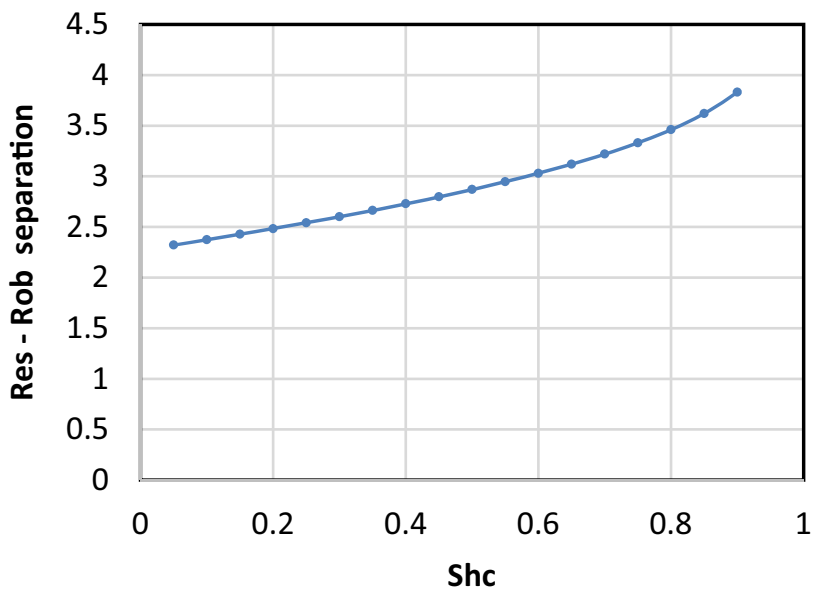

Fig. $22 S_{\mathrm{hc}}$ versus separation for $V_{\mathrm{c}}=25 \%, m=4$

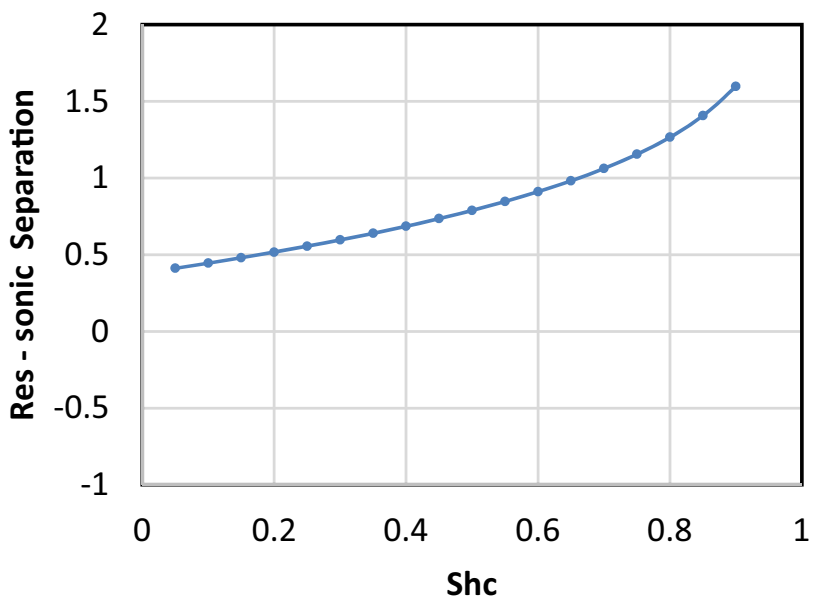

Fig. $23 S_{\mathrm{hc}}$ versus separation for $V_{\mathrm{c}}=25 \%, m=4$

cases, resistivity-density and resistivity-sonic for the entire range of $S_{\mathrm{w}}$ or $S_{\mathrm{hc}}$

Figures 16 and 17 show the nonlinear correlations for the case of no clay and $m=2$ and low porosity $\Phi=10 \%$. representing clean formation and inter-particle pore structure. The two figures show that the relationship is still nonlinear for both cases, resistivity-density and resistivity-sonic.

Figures 18, 19, 20 and 21 show that the nonlinear correlation also holds for the forward modeled cases of $V_{\mathrm{c}}=25 \%, V_{\mathrm{c}}=50 \%$ and $m=2$ representing the inter-particle pore structure case, with variable clay volume.

Similarly, Figs. 22 and 23 show that the nonlinear correlation still holds for the forward modeled cases of $V_{\mathrm{c}}=25 \%$ and $m=4$ representing the vuggy pore structure.

The reason that the linear assumption is acceptable in the unconventional reservoirs is because the range of the 
Comparison between modeled and calculated hydrocarbon saturation

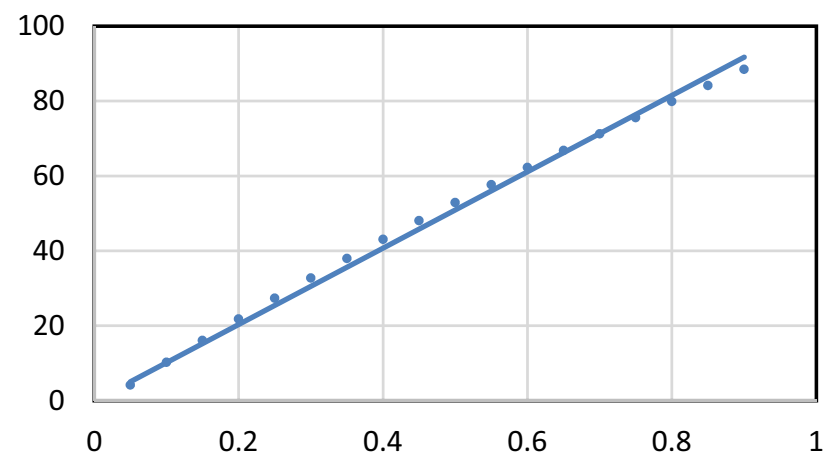

Fig. 24 Hydrocarbon saturation from density

\section{Comparison between modeled and calculated} hydrocarbon saturation

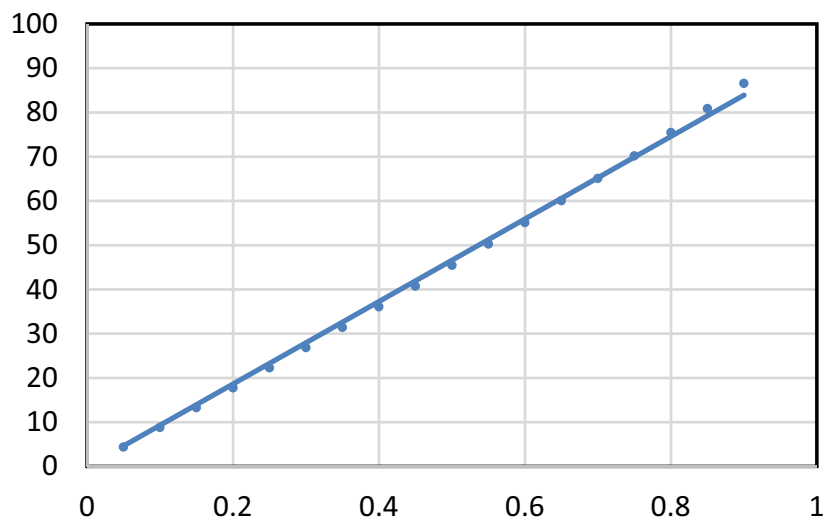

Fig. 25 Hydrocarbon saturation from sonic

TOC is between 0 and $10 \%$ at the most. In this range, the relation is linear and far from the nonlinear range.

In conventional reservoirs, the relationship is found to be a nonlinear exponential function. It takes the form

$S_{\mathrm{hc}} \propto e^{-(\Delta R+\Delta \rho)} \rightarrow S_{\mathrm{hc}}=1+a e^{-(\Delta R+\Delta \rho)}$

The coefficient $(a)$ can be easily determined using a water zone in the reservoir where $S_{\mathrm{hc}}=0$ and hence

$a=-\frac{1}{e^{-(\Delta R+\Delta \rho)}}$

\section{Comparison between modeled and calculated hydrocarbon saturation}

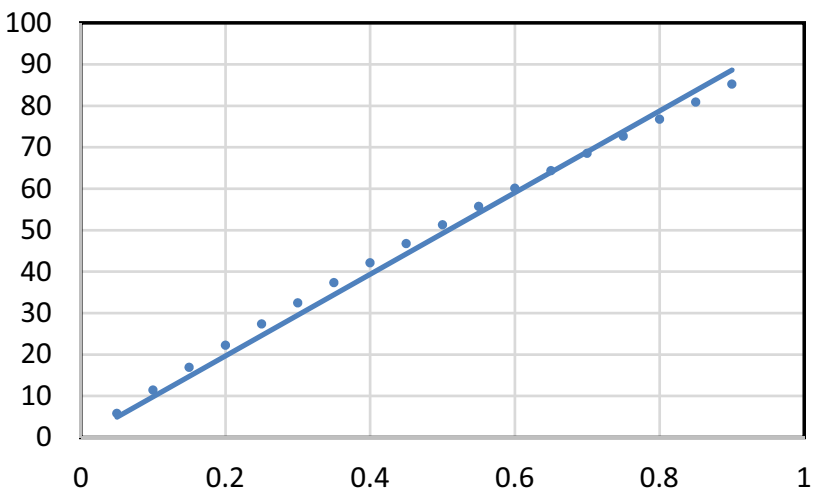

Fig. 26 Hydrocarbon saturation from density

\section{Comparison between modeled and calculated hydrocarbon saturation}

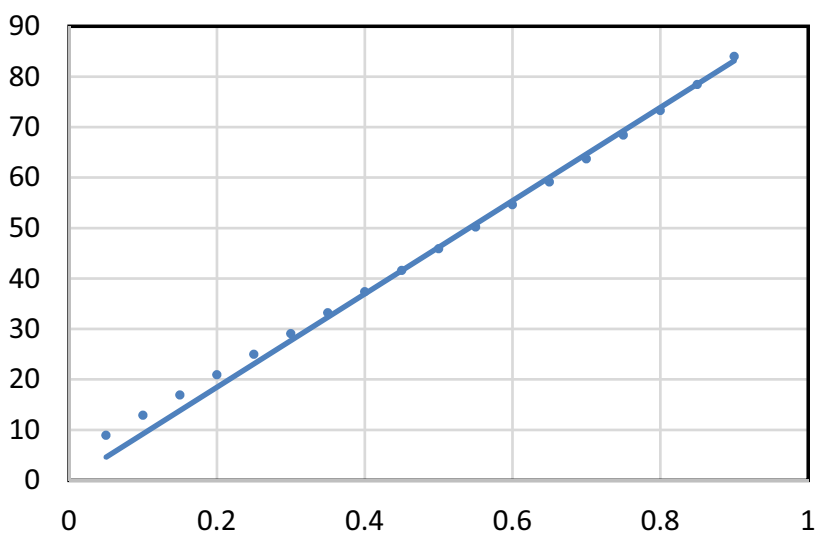

Fig. 27 Hydrocarbon saturation from sonic

\section{Evaluation of the methodology}

The model is evaluated using the forward model example and actual fields data. For the forward modeled example, the calculated hydrocarbon saturation using Eqs. (16) and (17) is compared to the input hydrocarbon saturation.

Figures 24 and 25 show the comparison for the case of $V_{\mathrm{c}}=0, m=2$ and $\Phi=30 \%$ where excellent agreement is obtained for both cases; resistivity-density and the resistivity-sonic, respectively. The maximum difference observed is 3.0 saturation units. The value of the coefficient $(a)$ using Eq. (17) is determined using the $100 \%$ water saturation point, $a=-3.685$ and $a=-0.7411$ for density and sonic, respectively. 
Comparison between modeled and calculated saturation

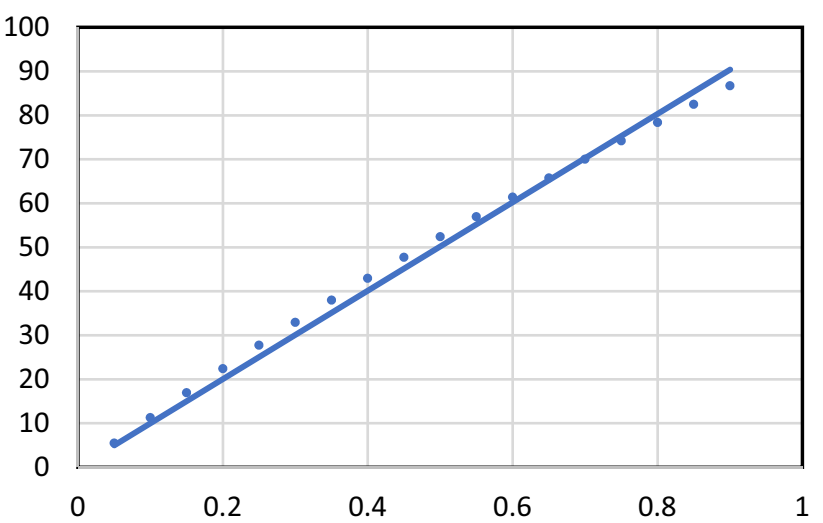

Fig. 28 Hydrocarbon saturation from density

Comparison between modeled and calculated hydrocarbon saturation

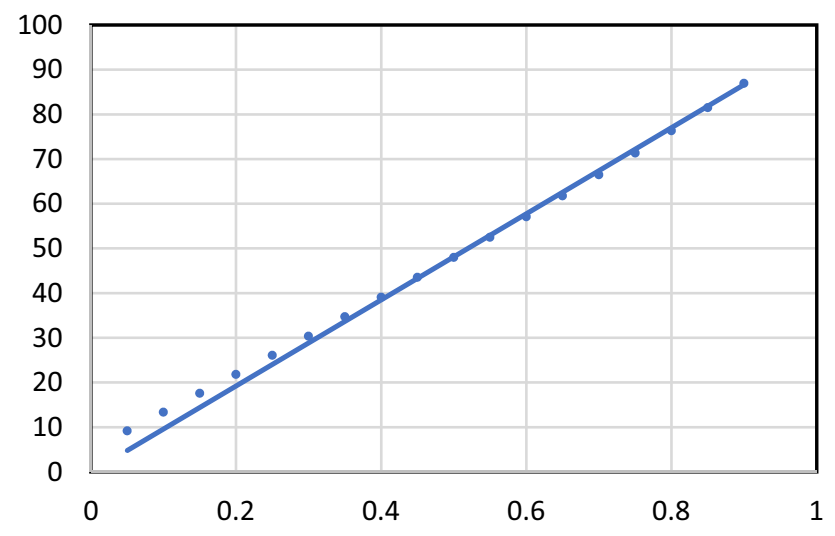

Fig. 29 Hydrocarbon saturation from sonic

Figures 26 and 27 show the comparison for the case of $V_{\mathrm{c}}=0, m=2$ and $\Phi=10 \%$ where excellent agreement is obtained for both cases; resistivity-density and the resistivity-sonic, respectively. The maximum difference observed is still in the order of 3.0 saturation units. The value of the coefficient ( $a$ ) using Eq. (17) is determined using the $100 \%$ water saturation point, $a=-1.46$ and $a=-0.189$ for density and sonic, respectively.

Figures 28 and 29 show the comparison for the case of $V_{\mathrm{c}}=25 \%, m=2$ and $\Phi=30 \%$ where excellent agreement is also obtained for both cases; resistivity-density and the resistivity-sonic, respectively. The maximum difference observed is 4.0 saturation units. Similarly, the value of the coefficient (a) using Eq. (17) is determined using the $100 \%$ water saturation point, $a=-4.69$ and $a=-0.708$ for density and sonic, respectively.
Comparison between modeled and calculated saturation

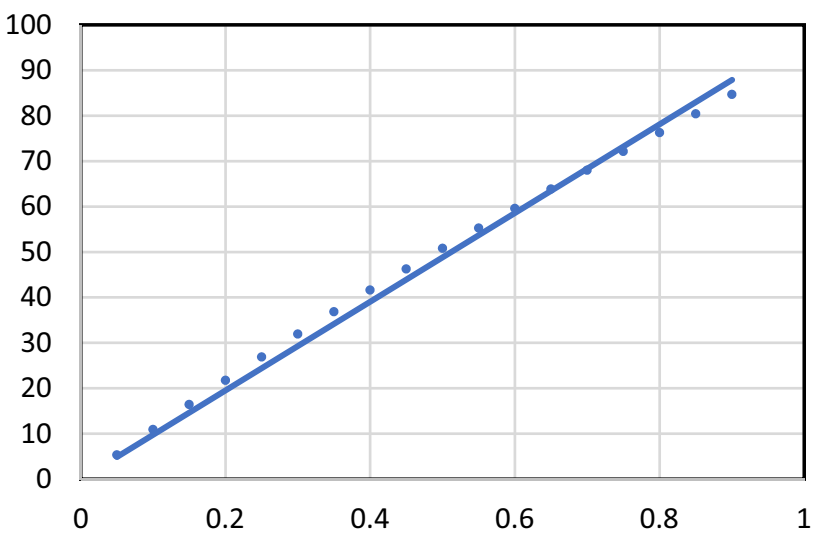

Fig. 30 Hydrocarbon saturation from density

\section{Comparison between modeled and calculated hydrocarbon saturation}

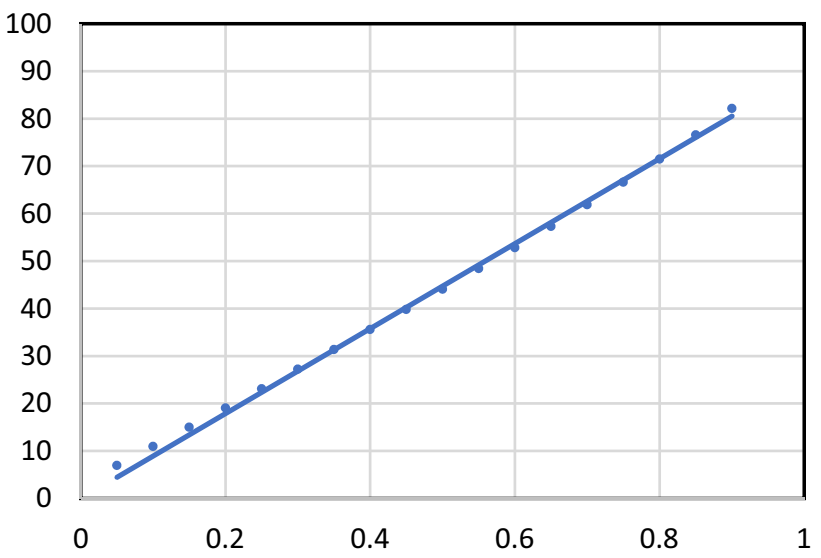

Fig. 31 Hydrocarbon saturation from sonic

Figures 30 and 31 show the comparison for the case of $V_{\mathrm{c}}=50 \%, m=2$ and $\Phi=30 \%$ where excellent agreement is also obtained for both cases; resistivity-density and the resistivity-sonic, respectively. The maximum difference observed is 4.5 saturation units. Similarly, the value of the coefficient (a) using Eq. (17) is determined using the $100 \%$ water saturation point, $a=-5.99$ and $a=-0.67$ for density and sonic, respectively.

Figures 32 and 33 show the comparison for the case of $V_{\mathrm{c}}=25 \%$ and $m=4$ for vuggy carbonate pore structure where excellent agreement is obtained for the case of resistivity-density, \pm 4 saturation units, while the resistivity-sonic showed higher disagreement, \pm 10 saturation units. The value of the coefficient $(a)$ using Eq. (17) is determined using the $100 \%$ water saturation 
Comparison between modeled and calculated saturation

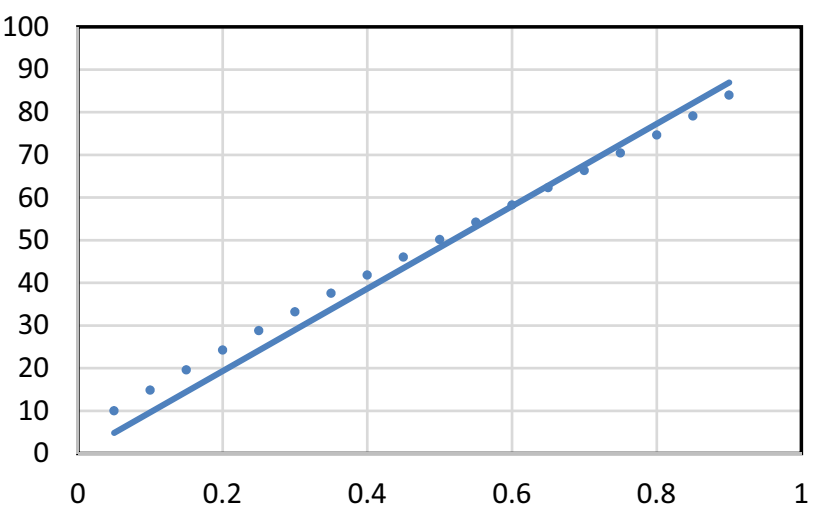

Fig. 32 Hydrocarbon saturation from density

Comparison between modeled and calculated hydrocarbon saturation

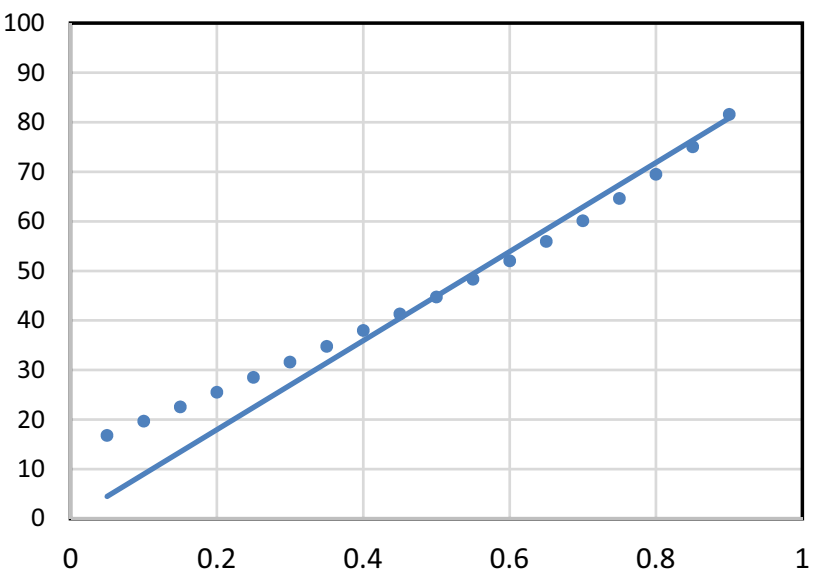

Fig. 33 Hydrocarbon saturation from sonic

point, $a=-1.062$ and $a=-0.12$ for density and sonic, respectively.

This high disagreement in the case of the resistivity-sonic only but not the resistivity-density is attributed to the inapplicability of the forward modeling of the sonic tool response in the case of vuggy formation using the Wyllie equation. This is confirmed by the fining of Baechle et al. (2007).

\section{Field applications}

The model is also tested in two actual wells, and comparisons with the Simandoux water saturation model are performed. Figure 34 shows the results of the first well.

The upper clay zone is used as the base zone where, $R_{\mathrm{b}}=1.66 \Omega$ and $\rho_{\mathrm{b}}=2.39 \mathrm{~g} / \mathrm{cc}$. Track- 6 shows the

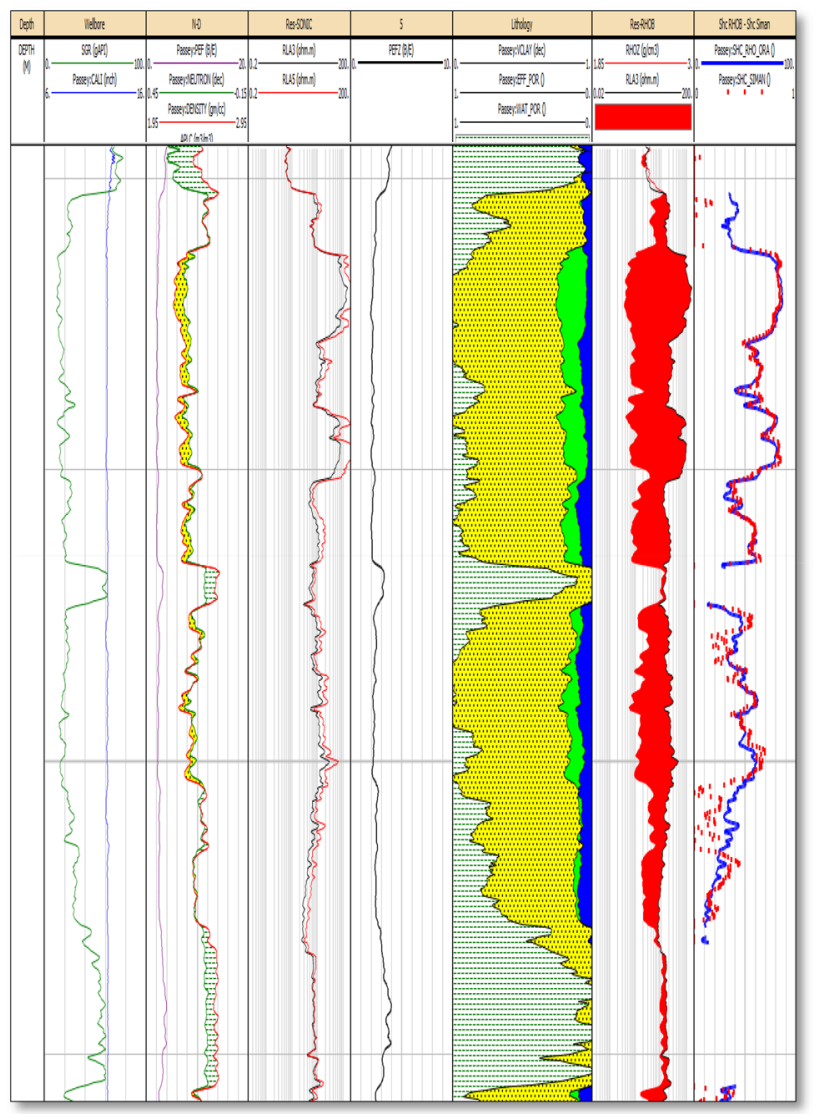

Fig. 34 Field application-sandstone

resistivity-density overlay where very clear separation is observed indicating hydrocarbon saturation. The lithology in track- 6 and the photo-electric values in track-5 show that the lithology of the formation is sandstone. The fluids saturation and the oil water contact based on Simandoux saturation model are also shown. The Simandoux parameters used in this well are $R_{\mathrm{w}}=0.11 \Omega @ 75^{\circ} \mathrm{F}, m=2.2$ and $n=2.0$ as indicated by the core measurements.

The model is applied using Eqs. 16 and 17. There are multiple water zones in this reservoir that are used to calculate the $(a)$ parameter from Eq. (17). The parameter $(t)$ equals to -1.465 for this reservoir.

Track-7 shows a comparison between the Simadoux hydrocarbon saturation in red dots and the model hydrocarbon saturation in solid line. Excellent agreements are obtained indicating the validity of the method. The calculated $S_{\mathrm{w}}$ using Simadoux model showed an abrupt change in the water saturation at the bottom of the lower zone that cannot be explained by fluids movement. The acceptable explanation is the increase in the clay volume that requires changing the electrical parameters $(m, n)$ to capture this increase in the clay volume effect on these electrical parameters. On the other hand, the resistivity-density separation 


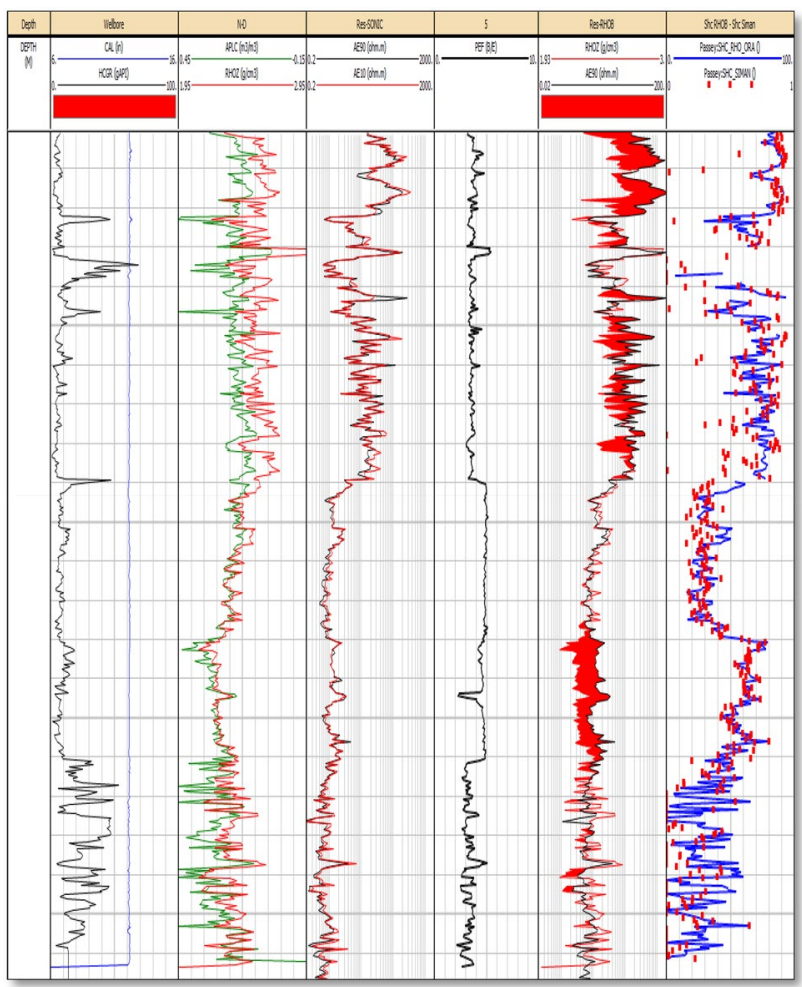

Fig. 35 Field application—carbonate

model did not show that abrupt change. This finding proved that the developed separation model adds values over the Archie-based saturation models

The second application, Fig. 35, is a carbonate reservoir under water injection. Track-4 contains the photo-electric factor, PeF, showing a value of (3) for the top and the bottom zones and a value of (5) for the middle zone. This shows that the top and the bottom zones of the reservoir are dolomite, while the middle zone is limestone.

Track- 5 shows the resistivity-density overlay using the lower clay zone as the base zone where, $R_{\mathrm{b}}=1.1 \Omega$ and $\rho_{\mathrm{b}}=2.42 \mathrm{~g} / \mathrm{cc}$. The overlay shows hydrocarbon separation in the top dolomite zone and in the bottom section of the middle limestone zone, while the upper section of the limestone zone shows no indication of hydrocarbon separation. The reason is the ongoing water injection activities. The upper zone has more sweeping efficiency due to its high intensity of fractures network as indicated by the imaging $\log$ in Fig. 36.

Track- 6 shows a comparison between the hydrocarbon saturation using Simandoux saturation model, red dots and the overlay separation model, blue line. The constant $(a)$ is obtained using the water zone, $a=-0.80$. The comparison shows some disagreement between the Simadoux and the model in the sweeping zone. This is because of the variation of the formation water salinity $R_{\mathrm{w}}$ in this zone that cannot be

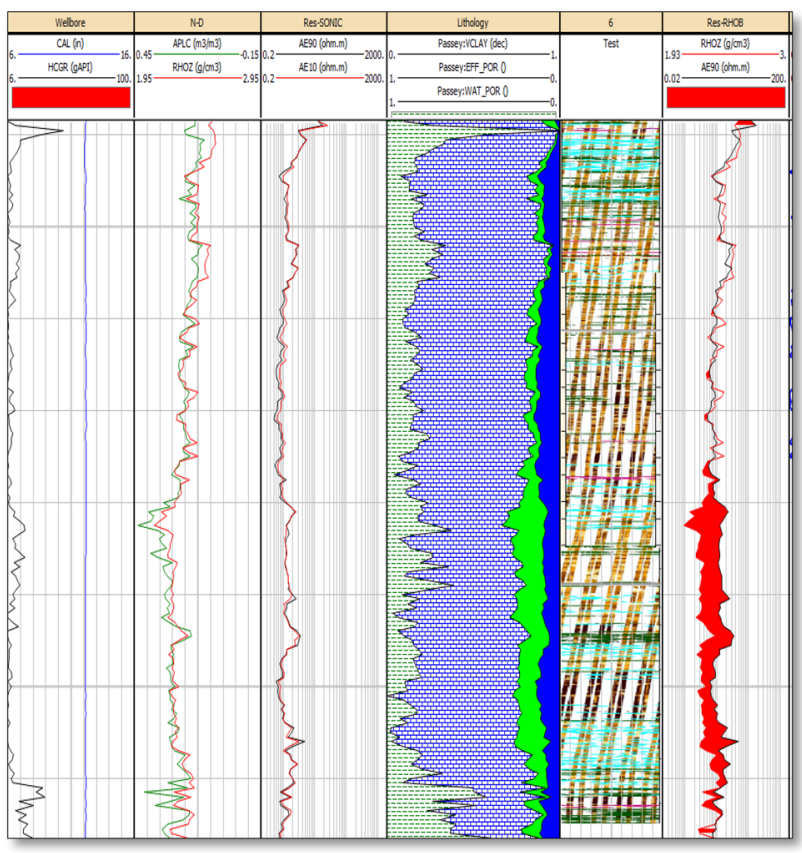

Fig. 36 Imaging $\log$

correctly handled by the Simadoux model. Also, when the gamma ray increases indicating clay effect, some disagreements between the model and the Simandoux water saturation are observed. This is due to the need for changing the electrical parameters $(m, n)$ as discussed in the first example.

\section{Conclusions}

The non-Archie resistivity-density and/or resistivity-sonic overlay method provides an excellent methodology to evaluate the hydrocarbon saturation without the need for the Archie-based models parameters $R_{\mathrm{w}}, m$ and $n$. The theoretical analysis of the model and the field applications show that the methodology is solid and practical.

\section{Recommendations}

In case of highly washed out borehole, it is recommended to use the resistivity-sonic overlay since the sonic travel time tools have deeper depth of investigation compared to the density tools. This will decrease the effect of the washout on the overlaid data and provide more reliable hydrocarbon saturation.

Open Access This article is licensed under a Creative Commons Attribution 4.0 International License, which permits use, sharing, adaptation, distribution and reproduction in any medium or format, as long as you give appropriate credit to the original author(s) and the source, provide a link to the Creative Commons licence, and indicate if changes

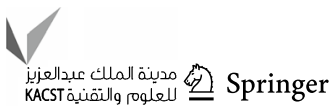


were made. The images or other third party material in this article are included in the article's Creative Commons licence, unless indicated otherwise in a credit line to the material. If material is not included in the article's Creative Commons licence and your intended use is not permitted by statutory regulation or exceeds the permitted use, you will need to obtain permission directly from the copyright holder. To view a copy of this licence, visit http://creativecommons.org/licenses/by/4.0/.

\section{References}

Archie GE (1942) The electrical resistivity log as an aid in determining some reservoir characteristics. Trans AIME 146(01):54-62

Baechle $\mathrm{G}$ et al (2007) Modeling velocity in cabonates using a dual-porosity DEM model. SEG technical program expanded abstracts

Clavier C, Coates G, Dumanoir J (1977) The theoretical and experimental basis for the dual water model for the interpretation of Shaly sand. SPWLA, Denver October 9-12
Focke JW, Munn D (1987) Cementation exponents in ME carbonate reservoirs. SPE Formation Evaluation

Passey Q et al (1990) A practical model for organic richness from porosity and resistivity logs. SPE, Denver

Passey Q et al (2010) From oil-prone source rock to gas-production Shale reservoir-geologic characterization of unconventional Shale-gas reservoirs. In: SPE 131350, international oil \& gas conference China June 8-10

Passey Q et al (2012) My source rock is now my reservoir-geologic and petrophysical characterization of Shale gas reservoirs. AAPG distinguished lecture

Simandoux P (1982) Dielectric measurements in porous media and applications in Shaly formations. Revue de l'Institute Francais de Petrole - SPWLA English Translation Volume Shaly Sand

Waxman M, Smits J (1968) Electrical conductivities in oil-bearing Shaly sand. SPE 8(02):107-122

Publisher's Note Springer Nature remains neutral with regard to jurisdictional claims in published maps and institutional affiliations. 